\title{
Intraoperative Transesophageal Echocardiography to Evaluate Pediatric Patients Undergoing Atrial Septal Defect Procedure
}

Marcello Fonseca Salgado Filho ${ }^{1 *}$, Maia Nogueira Crown Guimaraes ${ }^{2}$, Izabela Magalhaes Campos ${ }^{3}$ and Izabela Palitot da Silva ${ }^{4}$

${ }^{1}$ Professor of Anesthesiology, Department of Anesthesia, Federal University of Rio de Janeiro, Rio de Janeiro, Brazil

${ }^{2}$ Resident of Anesthesiology, Department of Anesthesia, Hospital of Juiz de Fora, Juiz de Fora, Brazil

${ }^{3}$ Anesthesiogist, Department of Anesthesia, Felício Rocho Hospital, Belo Horizonte, Brazil

${ }^{4}$ Professor of Nursing, Department of Nursing, Federal University of Juiz de Fora, Juiz de Fora, Brazil

\begin{abstract}
Introduction: Atrial septal defects (ASD) are a type of congenital heart disease that are characterized by a communication between the left atrium with the right atrium. Preoperative intraoperative transesophageal echocardiography (TEE) evaluates cardiac anatomy and function. The objective of this paper was to compare the use of intraoperative TEE in corrective surgeries for ASD in pediatric patients.
\end{abstract}

Material and Methods: After approval by the local Ethics Committee for Research, a retrospective descriptive study was conducted in children aged 3 to 18 years who underwent an ASD repair between January 2011 and January 2015 divided in two groups: TEE group $(n=24)$ and No-TEE group $(n=28)$. Were assessed the demographic data, Qp/Qs ratio, pulmonary hipertension (PH), left ventricle ejection fraction (EF), and major clinical outcomes.

Results: There were differences between the two groups in demographics data in age and wieght that were higher in the No-TEE group. There were no differences between the two groups in pulmonary infection, renal dysfunction, congestive heart failure, time of extubation in the ICU and intra-hospital mortality. There was $4 \%$ atrial arrhythmias in the TEE group and $0 \%$ in the No-TEE group $(p=0.46)$. The No-TEE group showed more time to wean from CPB (35.1 \pm 17.3 minutes vs $43.6 \pm 27.2$ minutes; $p=0.01)$ and more time to release from ICU than TEE-group ( $42 \pm 13.2$ hours vs $58.9 \pm 30.4$ hours, $p=0.01$ ).

Conclusions: We concluded that the use of intraoperative TEE is safe and economically feasible. It enables an assessment of cardiac anatomy and functions in the pre-CPB period and guide the weaning from CPB with lower time of CPB and ICU length stay than No-TEE group.

Keywords: Ultrasonography; Atrial septal defect; Pediatric patients.

\section{Introduction}

Congenital Heart Defects (CHD) have an incidence of between $0.7 \%$ and $1.0 \%$ of live births in the USA [1]. Chromosomal abnormalities are among the most common causes of cardiac malformation and are responsible for $10 \%$ of congenital cardiopathies [2]. The other $90 \%$ result from multifactorial causes, including complex gene interactions, rubella infection, maternal alcohol abuse or diabetes and the use of lithium during pregnancy [2]. The main signs and symptoms in patients with congenital heart disease are dyspnea, delayed physical development, low weight and cardiac murmurs [1,3].

CHD can be classified as shunt or obstructive types [1]. Atrial Septal Defects (ASDs) are classified as physiologically acyanotic cardiopathies with a shunt, which is most often a left-to-right shunt with increased pulmonary blood flow $[1,3]$. Anatomically, ASDs can be classified as Ostium Secundum (OS), Ostium Primum (OP), Sinus Venosus (SV), Coronary Sinus (CS) and patent foramen ovale $[1,2,4]$. The OS-type interatrial communication (IC) accounts for $80 \%$ of cases of ASD. Anatomically, it is located close to the fossa ovalis in the middle of the atrial septum and results from the incomplete formation of the septum secundum [3].

The OP-type IC originates from a defect in the formation of the endocardial cushion and septum primum, and is characterized by a large opening in the atrial septum [1,3]. It is located in the lower region of the right-sided septum, near the right Atrioventricular Valve (AV). Normally, the OP type is associated with a Ventricular Septal Defect (VSD) and malformation of the left and right AV valves, which results in a more complex CHD termed an Atrioventricular Septal Defect
(AVSD), which can be partial or total $[1,3]$. The SV-type ASD is located in the apical region of the septum, just below the junction with the Superior Vena Cava (SVC). It is sometimes associated with a right and/ or left Anomalous Pulmonary Venous Drainage (AVPD) [3]. The ICtype CS have persistent left SVC and may be associated with mitral valve prolapse [3].

Patent Foramen Ovale (PFO) is present in more than a third of normal subjects and results from the failed fusion of the septum primum with the septum secundum [4]. These patients may exhibit paradoxical air embolism during physical activity or during the Valsalva maneuver, which can cause severe neurological sequelae [4].

Over time, most of forms of ASD can result in pulmonary hypertension, circulatory overload and hypertrophy of the Right Ventricle (RV), leading to congestive heart failure [1-3]. The severity of the physiological changes depends on the size of the IC and the direction of flow, which is determined by the difference in resistance

*Corresponding author: Marcello Fonseca Salgado Filho, National Institute of Cardiology, Rua Sao Luiz, 281 CEP: 36039-010, Brazil, Tel: 55(32)99858833; E-mail: mfonsecasalgado@hotmail.com

Received September 06, 2014; Accepted May 13, 2015; Published May 15, 2015

Citation: Filho MFS, Guimaraes MNC, Campos IM, da Silva IP (2015) Intraoperative Transesophageal Echocardiography to Evaluate Pediatric Patients Undergoing Atrial Septal Defect Procedure. J Cardiovasc Dis Diagn 3: 199. doi:10.4172/23299517.1000199

Copyright: $\odot 2015$ Filho MFS, et al. This is an open-access article distributed under the terms of the Creative Commons Attribution License, which permits unrestricted use, distribution, and reproduction in any medium, provided the original author and source are credited. 
Citation: Filho MFS, Guimaraes MNC, Campos IM, da Silva IP (2015) Intraoperative Transesophageal Echocardiography to Evaluate Pediatric Patients Undergoing Atrial Septal Defect Procedure. J Cardiovasc Dis Diagn 3: 199. doi:10.4172/2329-9517.1000199

between the pulmonary and systemic vasculature [2,3]. A small ASD of $<0.5 \mathrm{~cm}$ in diameter gives rise to only a small shunt and few symptoms. However, defects with diameters that are larger than $2.0 \mathrm{~cm}$ result in a significant shunt, with increased pulmonary blood flow [3]. An IC with pulmonary and systemic blood flow ratios (Qp/Qs ratios) $<1.5$ do not require surgical correction, but those with $\mathrm{Qp} / \mathrm{Q}$ s ratios $>1.5$, which are associated with RV overload and pulmonary hypertension, should be treated surgically or percutaneously [1]. These interventions aim to reverse right-to-left shunts and severe hypoxemia $[1,3]$.

The current recommendation for percutaneous surgery is for OStype ASD with a diameter $<41 \mathrm{~mm}$ [4]. Unfortunately, the close proximity of the defect to the AV valves, coronary sinus or systemic venous drainage prevents the use of this technique. Percutaneous treatment is a safe procedure in experienced hands, with complications occuring in less than $1 \%$ of patient $[1,3,4]$. The most common complications are perforation of the atrium, dislocation and embolization of the prosthesis, cardiac tamponade, thrombus formation and cardiac arrhythmias [4]. It would be the method of choice for adult patients because they present with chronic clinical conditions as a result of their ASD, such as atrial arrhythmias, RV overload and pulmonary vascular disease, which would increase mortality when undergoing surgery with cardiopulmonary bypass (CPB) [3,4]. Children with OS-type ASD have a good response to open-heart surgery, but surgery is also recommended for other types of ASD [1,3].

Several studies have demonstrated the usefulness of intraoperative Transesophageal Echocardiography (TEE) surgery for the correction of CHD [1,3,5-7]. TEE can reveal details of the morphology and physiology of the heart in most surgical cases [5-7]. Prior to CPB, this information can influence anesthetic or surgical planning [6]. After the completion of $\mathrm{CPB}$, it is possible to have immediate access to parameters that assess the outcome of surgery, as well as the hemodynamic cardiac characteristics [5]. TEE is useful in the diagnosis of immediate residual shunts and ventricular dysfunction after $\mathrm{CPB}$, which increase the incidence of repeat surgery and mortality rates [3,5-7].

This study aimed to compare the clinical outcomes of intraoperative TEE during ASD procedures.

\section{Materials and Methods}

After approval was gained from the Research Ethics Committee of Santa Casa de Misericordia de Juiz de Fora, and in accordance with the standards of the Declaration of Helsinki, a retrospective analysis was conducted of the medical records of 59 consecutive patients with ASD who underwent open surgical repair between January 2011 and January 2015 were divided in two groups: Goup TEE $(\mathrm{n}=28)$ and Group no-TEE (N=31).

The inclusion criteria were pediatric patients (ages between 3 and 18 years old) and both genders who were undergoing an open surgical repair of a on-pump ASD. Exclusion criteria included adult patients (>18 years), emergency surgery and patients with tetralogy of Fallot, tricuspid atresia, pulmonary atresia, transposition of the great vessels or other complex congenital heart disease associated with their ASD.

\section{Anesthetic procedure}

In the operation room, a standart monitoring was performed. The patients were underwent general anesthesia with midazolam, ketamin, cisatracurium and fentanyl with controled ventiltion. After intubation, a invasive arterial pressure and central venous pressure monitoring was performed.

\section{TEE Procedure}

In the TEE group, the exames were performed by a anesthesiologist trained in intraoperative TEE. When the patient was intubated, the oropharynx was lubricated and a multiplane probe with a frequency of $8 \mathrm{MHz}$ TEE (Vivi I', GE, Helsinki, Phinland, 2011) was introduced. Echocardiographic examinations were performed in accordance with the criteria of the Society of Cardiovascular Anesthesiologist (SCA) [811]. The TEE analysis was performed in all patiets of this group and was assessment the ejection fraction (Simpson's techquenic), cardiac output (continuos equation), pulmonary arterial systolic pressure (Bernoulli equation in the tricuspide regurgitation) and the right ventricle myocardial performance index (pulse Doppler in the DTG view between anterior mitral valve and LVOT) in the pre-CPB period before the surgical incision, during the weaning from $\mathrm{CPB}$, and post$\mathrm{CPB}$ period, 10 minutes after protamine [12-14].

\section{Outcomes analysis}

The following clinical parameters were assessed in both groups: i) perioperative heart failure, defined by the necessity of using ventricular support device or use of inotropic drugs or vasopressors for more than 48 hours; ii) perioperative renal dysfunction, defined as serum creatinine being greater than or equal to $2.0 \mathrm{mg} / \mathrm{dl}$, accompanied by a baseline increase of $0.7 \mathrm{mg} / \mathrm{dl}$; iii) renal failure, defined as renal dysfunction requiring hemodialysis; iv) atrial arrhythmias; v) use of inotropic drugs at the end of $\mathrm{CPB}$; vi) total duration of $\mathrm{CPB}$ and aortic clamping; vii) need for red blood cell transfusion; viii) duration of intubation in the intensive care unit (ICU); ix) length of stay in the ICU; and $\mathrm{x}$ ) intra-hospital mortality.

\section{Statistical analysis}

We used the Student's t-test or Mann-Whitney test, according to the normality test (Kolmogorov-Smirnov), to compare the continuous variables between groups, and the categorical data were analyzed using the Chi-square test. Statistical analysis was performed using the Graph Pad OS5 program for Macintosh. Parametric and non-parametric data were expressed as the mean \pm SD and the frequency or percentage for nominal variables. Statistical significance was set as $\mathrm{P}$ values below $5 \%$.

\section{Results}

Corrective ASD surgeries were performed on 59 patients from January 2011 to January 2015, and TEE was used in 28 patients, but four patients were excluded in this group, because they were older than 18 years old and in the no-TEE group, 3 patients were excluded, because they were younger than 3 years old. Thus, the patients were divided in two groups: Goup TEE $(\mathrm{n}=24)$ and Group No-TEE $(\mathrm{N}=28)$ (Figure 1).

Table 1 shows the demographic data of patients. There were statistical difference in age and wieght between the groups (Table 1).

Table 2 shows the clinical outcomes, the inotropic used during weaning from $\mathrm{CPB}$ and the time of $\mathrm{CPB}$ and the aortic cross-clamping time (Table 2).

\section{Discussion}

In this study, $75 \%$ of patients were female in TEE group and $71 \%$ in the No-TEE group. According to Baumgartner, the prevalence of ASD can be 2-3 times higher in females than males [3].

The ASD Ostium Secundun affects approximately $75 \%$ of patients $[1,3]$. Other types of ASD are less prevalent, as: Ostium Primum and 
Citation: Filho MFS, Guimaraes MNC, Campos IM, da Silva IP (2015) Intraoperative Transesophageal Echocardiography to Evaluate Pediatric Patients Undergoing Atrial Septal Defect Procedure. J Cardiovasc Dis Diagn 3: 199. doi:10.4172/2329-9517.1000199

Page 3 of 5

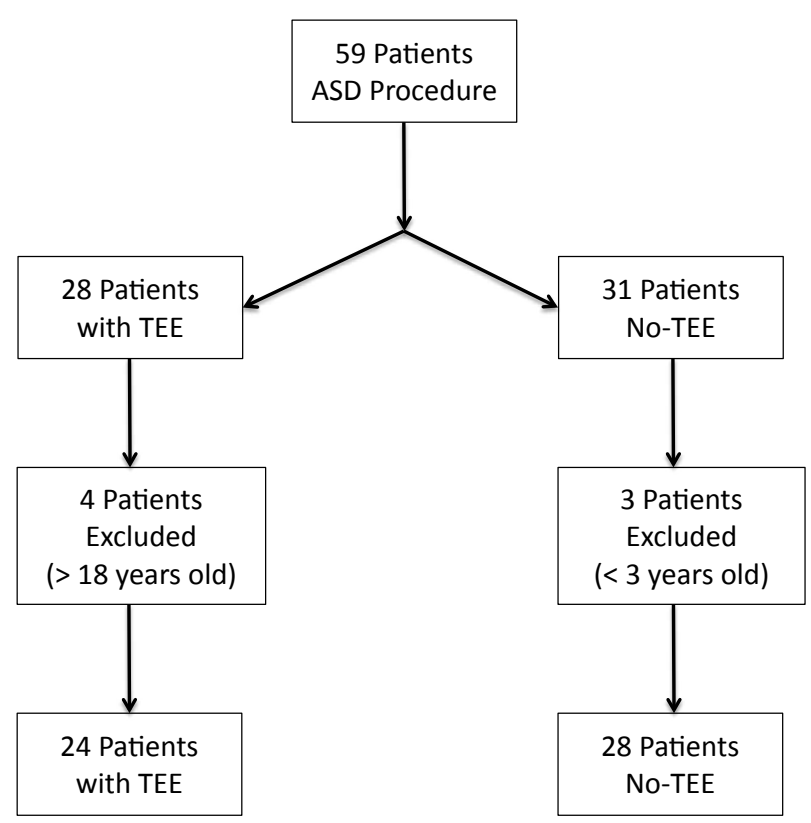

Figure 1: Study design- ASD: Atrial Septal Defect; TEE: Transesophageal Echocardiography.

\begin{tabular}{|c|c|c|c|}
\hline Data & TEE & No-TEE & P Value \\
\hline Number of Patients, $\mathrm{n}$ & 24 & 28 & 0.55 \\
\hline Age, years & $10.4 \pm 3.9$ & $5.9 \pm 3.5$ & $<0.0001^{*}$ \\
\hline Female gender, $\mathrm{n}(\%)$ & $18(75)$ & $20(71)$ & 1 \\
\hline Weight, Kg & $27.7 \pm 10.3$ & $15.5 \pm 15.1$ & $0.0001^{*}$ \\
\hline ASD OS, $\mathrm{n}(\%)$ & $18(85)$ & $21(91)$ & 0.65 \\
\hline ASA > 3,n (\%) & $24(100 \%)$ & $28(100)$ & 1 \\
\hline Lengh ASD, cm & $1.3 \pm 0.6$ & $1.2 \pm 0.4$ & 0.84 \\
\hline Qp/Qs & $2.1 \pm 1$ & $2.2 \pm 0.4$ & 0.7 \\
\hline PH, mmHg & $49.3 \pm 16.4$ & $41.2 \pm 15.4$ & 0.60 \\
\hline EF, $(\%)$ & $62.1 \pm 15.7$ & $71.3 \pm 6.4$ & 0.64 \\
\hline
\end{tabular}

ASD OS: Atrual septum defect Ostio Secundum; ASA: Patient phisics status; Qp/Qs: Relation of pumonic outflow and sistemic outflow; PH: Pulmonary Hipertension; EF: Ejection Frection; *Least P-value

Table 1: Patient demographics data.

Seio Venus defects are associated [1,3]. In our study, we observed a higher incidence os ASD OS with no difference with the two groups [15].

OS-type ASD, is located at mid-septal region in the oval fossa. TEE assessment in the region of the atrial septum at its cephalocaudal axis is well viewed in the 4-chamber ME interface and at a 120 degree to bicaval plane (Figure 2) $[6,15]$. Another plane at the ME through which one can view the OS-type ASD is between 30-60 degrees on the short axis of the aortic valve $[6,15]$.

A characteristic of ASD is volume overload from the right of the heart, because there is a connection between a low pressure cavity (right), and a higher pressure one (left), diversion of blood from left to right occurs (shunt) [2]. Thus, there is an increased pulmonary blood flow, with volumetric RV and PA overflow [1]. Over time, this can result in intimal hypertrophy of the PA with consequent pulmonary hypertension $(\mathrm{PH})$ and development of Obstructive Pulmonary Vascular Disease. When PH reaches systemic levels, there may be a reversal of the shunt left/right (Eisenmenger syndrome) with severe hypoxemia and paradoxal embolism [1].

Patients with Qp/Qs> 1.5 present indication of surgical correction of ASD [1]. In this study, all patients in bouth groups showed L-R shunt, and Qp/Qs values and $\mathrm{PH}$ showed no difference between the groups, although the values in both groups were incresed.

In most cases, the left ventricle function was preserved in both groups with normal EF and no difference between them. The increased blood flow to the RV may compromise its function of relaxation and contraction. In assessing the RV, the measure of MPI or RV Tei index is well recommended for assessing systolic and diastolic parameters in a single moment. This way you can perform a comprehensive analysis of right ventricular function $[12,16]$.

The MPI began to be studied from the ' 90 s and was aimed at non-invasive quantification of RV function in patients with primary pulmonary hypertension [12]. This index, measured by the Doppler method consists of the sum of isovolumetric contraction time with isovolumetric relaxation time divided by ejection time (Figure 3) [12].

The Tei index (MPI) is an easy to perform technique, not requiring the delineation of the endocardial border of the ventricle as used in measurement of ejection fraction. It is not influeced by heart rate and blood pressure, and showed good inter observer correlation [12].

Only the TEE group could be assessment with this Doppler

\begin{tabular}{|c|c|c|c|}
\hline \multirow{2}{*}{ Datas } & ETE & No-ETE & \multirow{2}{*}{ p Value } \\
\hline & $\mathrm{N}=\mathbf{2 4}$ & $\mathrm{N}=\mathbf{2 8}$ & \\
\hline Post-operative pneumomia, n (\%) & $0(0)$ & $0(0)$ & 1 \\
\hline Need for RBP, patients (\%) & $0(26)$ & $3(10)$ & 0.23 \\
\hline Renal dysfunction, n (\%) & $0(0)$ & $0(0)$ & 1 \\
\hline Atrial arrhythmias, $\mathrm{n}(\%)$ & $1(4)$ & $0(0)$ & 0.46 \\
\hline Cerebral dysfunction, $n(\%)$ & $0(0)$ & $0(0)$ & 1 \\
\hline OTE time in the ICU, Hours & $4,8 \pm 8.2$ & $7.6 \pm 16.9$ & 0.17 \\
\hline Duration of ICU stay, Hours & $42 \pm 13.2$ & $58.9 \pm 30.4$ & $0.01^{*}$ \\
\hline Mortality within 30 days, $\mathrm{n}(\%)$ & $1(4)$ & $1(3)$ & 1 \\
\hline $\begin{array}{l}\text { Inotropic drugs for weaning from } \\
\mathrm{CPB}, \mathrm{n}(\%)\end{array}$ & $8(33)$ & $3(14)$ & 0.18 \\
\hline Total time of CPB, min & $35.1 \pm 17.3$ & $43.6 \pm 27.2$ & 0.17 \\
\hline Total aortic clamp time, $\min$ & $23.8 \pm 15.1$ & $28.6 \pm 25.6$ & 0.58 \\
\hline
\end{tabular}

Table 2: Clinical outcomes, total time of $\mathrm{CPB}$ and total time of aortic clamping.

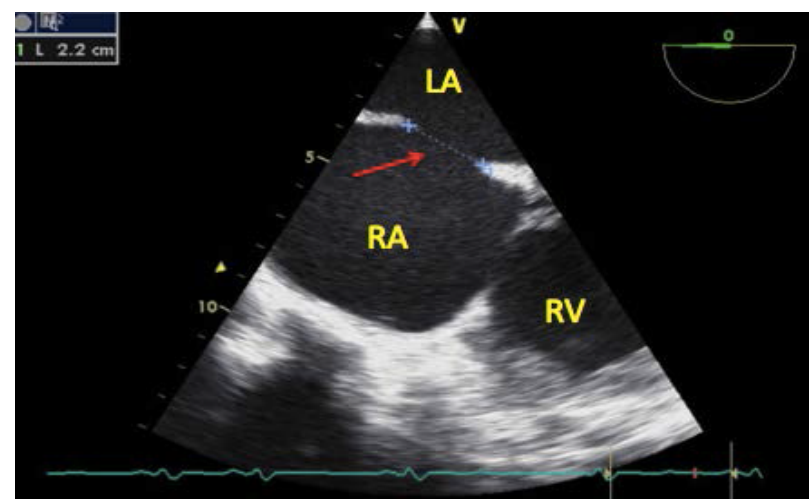

Figure 2: TEE mild esophagus 4 chamber view. Ostium secundum type ASD (red arrow): RA- right atrium; RV- right ventricle; LA- left atrium. 


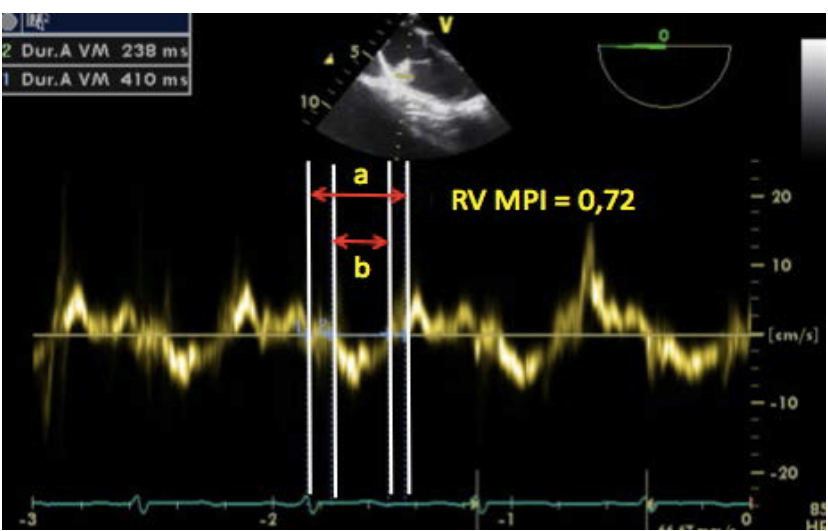

Figure 3: Measurement the right ventricle myocardial performance index (RV $\mathrm{MPI}$ ) by Tissure Doppler at the lateral ring the right atrioventricular valve in the mild esophagus four-chamber view. Distance 1 (a): time of isovolumetric contraction + isovolumic relaxation time; Distance 2 (b): time of ventricular ejection phase.

parameter, and the averege values of RV MPI was $0.85 \pm 0.49$. Salgado et al. reported that elevated RV MPI values were found in patients with manifestations of $\mathrm{PH}$ and this assessment can orient the inotropic and vasodilator suport and the volume requeriment during the weaning from CPB [13].

In this study there was no presence of residual shunt after surgical repair and it was not necessary to repeat $\mathrm{CPB}$ in any of the cases in bouth groups. Bettex et al. in an observational study conducted in two centers, evaluated the use of TEE in pediatric congenital heart surgery [7]. A total of 865 examinations were performed between January 1994 and March 2002. The incidence of repeated CPB, resulting not only from the findings of TEE, but also clinical signs, was 7.3\%. The biggest impact of the use of TEE occurred in corrections of more complex congenital heart defects [7]. Their results confirmed the potential benefit of using TEE in identifying problems in the intraoperative period that would require immediate surgery.

In another study, Bettex et al. evaluated the cost-effectiveness of routine use of TEE in pediatric congenital heart surgery over the course of 10 years experience [17]. Concluded that its use was not only safe and clinically beneficial but also cost-effective in the pediatric population. He points out that several studies have already investigated this end point in surgery for congenital heart defects in adults with the same conclusion [17].

TEE guides the performance of the LV and RV, thus, help in defining the best inotropic drug to be used during weaning from $\mathrm{CPB}$ $[7,18]$. Adrenaline in beta-adrenergic doses is widely used in congenital heart disease by acting as a beta-agonist on receptors in the LV and RV. This improves systolic function with no significant increase in heart rate when compared to the use of dobutamine [19]. Milrinone, an inodilator agent, inhibits the action of phosphodiesterase type III, acting on the RV and the PA, causing vasodilation, decreasing RV afterload and improving their MPI $[20,21]$.

ASD are congenital heart diseases with 30-day mortality rates of less than $2 \%$, and ICU stays less than 48 hours [22]. Our study shows similar results to the literature in both groups, with no difference between them, although the No-TEE group showed more time of delay to release from ICU than TEE-group ( $42 \pm 13.2$ hours vs $58.9 \pm$ 30.4 hours, $\mathrm{p}=0.01$ ). Some authors have shown that extubation in the operating room can be advantageous because it has a lower degree of atelectasis and lower risk of postoperative lung infection [23]. However, all patients in both groups in this study were extubated in the ICU, and the average of time to extubation $4.8 \pm 8.2$ hours in the TEE group and $7.6 \pm 16.9$ in the No-TEE group, without statistical difference. There were no pulmonary infection, renal dysfunction and congestive heart failure. There was $4 \%$ atrial arrhythmias in the TEE group and $0 \%$ in the No-TEE group $(\mathrm{p}=0.46)$.

Thus, we conclude that intraoperative TEE guide the weaning from $\mathrm{CPB}$, with lower time of CPB and ICU lenght stay than No-TEE group. The use of TEE is safe and economically feasible. It enables an assessment of cardiac anatomy and function pre-CPB, which enables an appropriate anesthetic/surgical approach and facilities the weaning from CPB. Post-CPB TEE enables the effectiveness of surgical correction to be evaluated, in addition to identifying any residual shunt and indicating whether a return to CPB is necessary.

\section{Acknowledgements}

There was no-financial support for this study. Special acknowledgements for the surgery team envolved in this study.

\section{Conflicts of Interest}

Conflict of interest: none declared.

\section{References}

1. Warnes CA, Williams RG, Bashore TM, Child JS, Connolly HM, et al. (2008) ACC/AHA 2008 guidelines for the management of adults with congenital heart disease. JACC 52: 1890-1947.

2. Silversides CK, Dore A, Poirier N, Taylor D, Harris L (2010) Canadian cardiovascular society 2009 consensus conference on the management of adults with congenital heart disease: Shunt lesions. Can J Cardiol 26: 70-79.

3. Baumgartner $\mathrm{H}$, Bonhoeffer $\mathrm{P}$, Groot NMSD, Haan Fd, Deanfield JE, et al. (2010) Esc guidelines for the management of grown-up congenital heart disease (new version 2010). European Heart Journal 31: 2915-2957.

4. Johansson MC, Eriksson P, Dellborg M (2009) The significance of patent foramen ovale: a current review of associated conditions and treatment. Int J Cardiol 134: 17-24.

5. Mertens L, Friedberg MK (2009) The gold standard for noninvasive imaging in congenital heart disease: echocardiography. Curr Opin Cardiol 24: 119-124.

6. Ayres NA, Miller-Hance W, Fyfe DA, Stevenson JG, Sahn DJ, et al (2005) Indications and guidelines for performance of transesophageal echocardiography in the patient with pediatric acquired or congenital heart disease. A report from the task force of the pediatric council of the american society of echocardiography. J Am Soc Echocardiogr 18: 91-98.

7. Bettex DA, Schmidlin D, Bernath M-A, Prêtre R, Hurni M, (2003) Intraoperative transesophageal echocardiography in pediatric congenital cardiac surgery: A two-center observational study. Anesth Analg 97: 1275-1282.

8. Shanewise JS, Cheung AT, Aronson S, Stewart WJ, Weiss RL, et al. (1999) ASE/SCA guidelines for performing a comprehensive intraoperative multiplane transesophageal echocardiography examination: Recommendations of the american society of echocardiography council for intraoperative echocardiography and the society of cardiovascular anesthesiologists task force for certification in perioperative transesophageal echocardiography. Anesth Analg 12: 884-900.

9. Thys D, Abel M, Brooker R, Cahalan M, Connis R, et al. (2010) Practice guidelines for perioperative transesophageal echocardiography. An updated report by the american society of anesthesiologists and the society of cardiovascular anesthesiologists task force on transesophageal echocardiography. Anesthesiology 112: 1084-1096.

10. Filho MF, Siciliano A, Diego LA, Miana LA, Salgado J (2011) [Transesophagea echocardiography in Ross procedure]. Rev Bras Anestesiol 61: 344-350.

11. Douglas PS, Khandheria B, Stainback RF, Weissman NJ, Brindis RG, et al (2007) Accf/ase/acep/asnc/scai/scct/scmr 2007 appropriateness criteria for transthoracic and transesophageal echocardiography. A report of the american college of cardiology foundation quality strategic directions committee 
Citation: Filho MFS, Guimaraes MNC, Campos IM, da Silva IP (2015) Intraoperative Transesophageal Echocardiography to Evaluate Pediatric Patients Undergoing Atrial Septal Defect Procedure. J Cardiovasc Dis Diagn 3: 199. doi:10.4172/2329-9517.1000199

Page 5 of 5

appropriateness criteria working group, american society of echocardiography, american college of emergency physicians, american society of nuclear cardiology, society for cardiovascular angiography and interventions, society of cardiovascular computed tomography, and the society for cardiovascula magnetic resonance endorsed by the american college of chest physicians and the society of critical care medicine. J Am Coll Cardiol 50: 187-204.

12. Lakoumentas JA, Panou FK, Kotseroglou VK, Aggeli KI, Harbis PK (2005) The Tei index of myocardial performance: applications in cardiology. Hellenic $J$ Cardiol 46: 52-58.

13. Salgado AA, Filho FMA, Castier M, Bedirien R (2004) Índice de performance miocárdica: Fim da fração de ejeção? Revista Brasileira de Ecocardiografia 17: 69-74.

14. Skubas N, Perrino A (2011) Assessment of perioperative hemodynamics. In Comprehensive textbook of perioperative transesophageal echocardiography, 2nd edition. Edited by savage rm, aronson s, shernan sk. Lippincott Williams \& Wilkins: 406-425

15. Burch TM, Mizuguchi KA, DiNardo JA (2012) Echocardiographic assessment of atrial septal defects. Anesth Analg 115: 772-775.

16. Haddad F, Couture P, Tousignant C, Denault AY (2009) The right ventricle in cardiac surgery, a perioperative perspective: I. Anatomy, physiology, and assessment. Anesth Analg 108: 407-421.

17. Bettex DA, Pre^tre R, Jenni R, Schmid ER (2005) Cost-effectiveness of routine intraoperative transesophageal echocardiography in pediatric cardiac surgery: A 10-year experience. Anesth Analg 100: 1271-1275

18. Hasenfuss G, Teerlink JR (2011) Cardiac inotropes: current agents and future directions. Eur Heart J 32: 1838-1845.

19. Butterworth JF IV, Prielipp RC, Royster RL, Spray BJ, Kon ND, et al. (1992) Dobutamine increases heart rate more than epinephrine in patients recovering from aortocoronary bypass surgery. Journal of Cardiothoracic \& Vascular Anesthesia 6: 535-541.

20. Feneck RO, Sherry KM, Withington PS, Oduro-Dominah A; European Milrinone Multicenter Trial Group (2001) Comparison of the hemodynamic effects of milrinone with dobutamine in patients after cardiac surgery. J Cardiothorac Vasc Anesth 15: 306-315.

21. Borow KM NA, Lang RM (1986) Milrinone versus dobutamine: Contribution of altered myocardial mechanics and augmented inotropic state to improved left ventricular performance. Circulation 73: 153-161

22. Galal MO, Wobst A, Halees Z, Hatle L, Schmaltz AA, et al. (1994) Perioperative complications following surgical closure of atrial septal defect type ii in 232 patients--a baseline study. Eur Heart J 15: 1381-1384.

23. Abuchaim DC, Bervanger S, Medeiros SA, Abuchaim JS, Burger M, et al (2010) Early extubation in the operating room in children after cardiac heart surgery. Rev Bras Cir Cardiovasc 25: 103-108. 